\title{
Rectangular loop suture to correct iris capture of the posterior chamber intraocular lens
}

\author{
Ke Lin, Zhixiang Hu, Zhong Lin, Tianyu Chen, Yongping Tang and Ronghan $\mathrm{Wu}^{*}$
}

\begin{abstract}
Background: To report a new technique for iris capture of the posterior chamber intraocular lens (IOL) implanted in patients with a posterior capsule defect.

Methods: In this retrospective case series, a rectangular loop ciliary body suture technique was performed to rectify iris capture. The suture passes between the IOL and iris in a direction perpendicular to the iris edge capturing the IOL.

Results: A total of three IOLs with iris capture underwent a rectangular loop suture technique. No recapture was observed postoperatively. In one case, large astigmatism appeared after the surgery but recovered at 1 month post operation. No further complications were found.

Conclusions: The rectangular loop suture technique is an effective, convenient, and minimally invasive method for iris capture of the IOL.
\end{abstract}

Keywords: Iris capture, Posterior chamber intraocular lens, Rectangular loop suture

\section{Background}

In eyes with a capsular defect, intracapsular intraocular lens (IOL) implantation is not possible. Accordingly, several alternative surgical techniques can be applied, including transscleral IOL fixation, sutureless intrascleral fixation, and the scleral hook technique [1-3]. While these have proven to be safe and effective, some complications remain, including suture breakage, IOL tilt or dislocation, haptic slip, and iris capture [4-6]. Cho and $\mathrm{Yu}$ reported an incidence of iris capture of $23 \%$ in patients who underwent combined scleral IOL fixation and pars plana vitrectomy. Iris capture leads to blurred vision, photophobia, and dull pain. Moreover, iritis and secondary glaucoma may occur during long-term iris capture [7].

\footnotetext{
* Correspondence: fundus033@163.com

Eye Hospital and School of Ophthalmology and Optometry, Wenzhou Medical University, 270 Xueyuan Road, Wenzhou 325000, Zhejiang Province, China
}

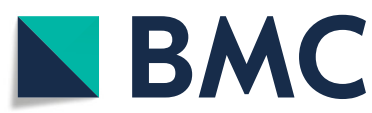

Iris capture of the IOL may be caused by pupil dilation [8], IOL deviation or tilt, a floppy iris [9], or reverse pupillary block [10]. Although pupil dilation or laser iridotomy of a reverse pupillary block are useful for iris capture, their success rates are relatively low [11-13]. When iris capture is not resolved by these techniques, surgical techniques can be applied, including IOL repositioning [12] and exchange [14]. However, these surgeries cause relatively large injuries and can result in bleeding and corneal endothelium loss. We performed a minimally invasive technique for three cases, and no iris recapture was observed post surgery.

\section{Methods}

\section{Surgical technique}

First, we design the route of sutures according to the appearance of patient's anterior segment. The sutures are perpendicular to the iris edge capturing the IOL preoperatively. For example, the direction of sutures in Fig. 1

(c) The Author(s). 2020 Open Access This article is licensed under a Creative Commons Attribution 4.0 International License, which permits use, sharing, adaptation, distribution and reproduction in any medium or format, as long as you give appropriate credit to the original author(s) and the source, provide a link to the Creative Commons licence, and indicate if changes were made. The images or other third party material in this article are included in the article's Creative Commons licence, unless indicated otherwise in a credit line to the material. If material is not included in the article's Creative Commons licence and your intended use is not permitted by statutory regulation or exceeds the permitted use, you will need to obtain permission directly from the copyright holder. To view a copy of this licence, visit http://creativecommons.org/licenses/by/4.0/ The Creative Commons Public Domain Dedication waiver (http://creativecommons.org/publicdomain/zero/1.0/) applies to the data made available in this article, unless otherwise stated in a credit line to the data. 


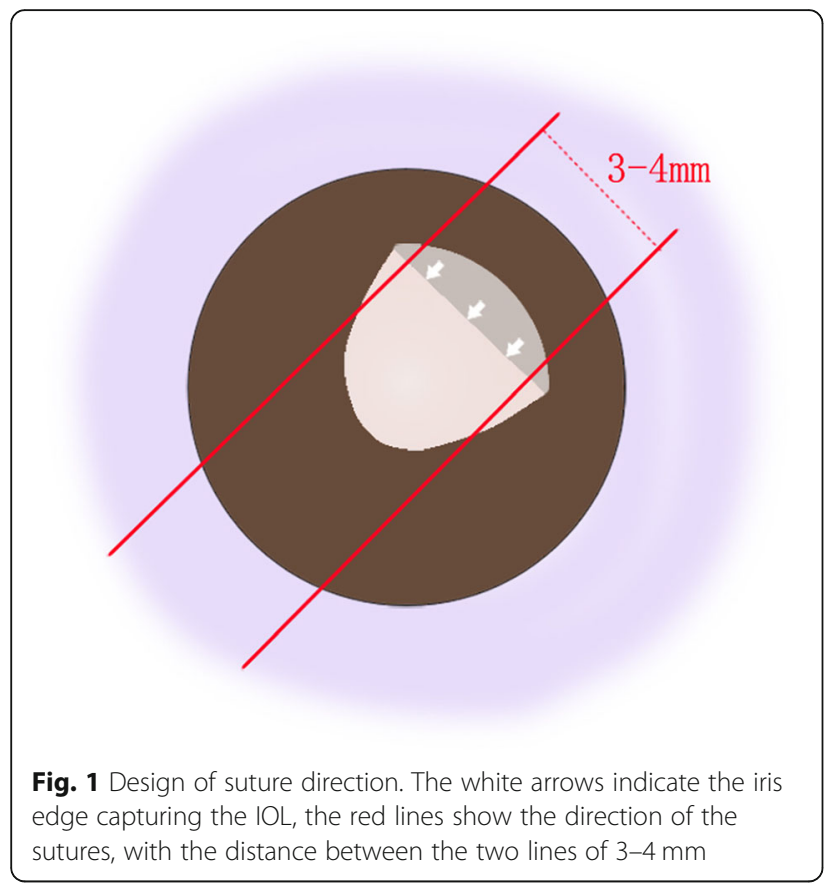

is 7:30 to 1:30 o'clock. After retrobulbar anesthesia, conjunctival incisions are made at the limbus from 1 to 2 o'clock and 7 to 8 o'clock to expose the sclera areas where the needles are going to be inserted through. Nonabsorbable 10-0 nylon suture with long straight needles is used. The needle is inserted into posterior chamber $2 \mathrm{~mm}$ behind the limbus at 1 o'clock, between the iris plane and IOL optic, and is externalized at 8 o'clock $2 \mathrm{~mm}$ behind the limbus with the assistance of a 26-gauge needle (Fig. 2a). Subsequently, the needle is inserted at 7 o'clock and withdrawn at 2 o'clock in the same manner (Fig. 2b). The suture is knotted and the knot is buried by rotating the loop into the vitreous cavity to avoid postoperative conjunctival irritation (Fig. 2c). The conjunctival incisions are sutured with 8-0 absorbable thread (Fig. 2d).

\section{Results}

\section{Case 1-left eye}

A 35-year-old female was diagnosed with bilateral subluxated lenses and underwent successful vitrectomy, phacoemulsification, and IOL intrascleral fixation for the left eye. After 3 months, the patient complained of a dull pain in the left eye and was diagnosed with iris capture of the IOL. Tropicamide and pilocarpine drops were given at 15-min intervals, and the iris capture was soon alleviated, but it reappeared within a few days. The IOL was subsequently repositioned to the pars plana to achieve a greater separation of the IOL and iris. Iris capture reappeared 1 month after the surgery, as shown in Fig. 3a. After 21 months, rectangular loop suture surgery was performed for the left eye. The corrected visual acuity was $0.4(-2.25 /-2.00 \times 5)$ preoperatively and improved to 0.5 one month after the surgery. Large astigmatism $(-1.00 /-5.50 \times 165)$ appeared after the surgery, with the astigmatism axis almost perpendicular to the suture direction. The astigmatism decreased to $2.75 \mathrm{D}$ at the one-month visit and to $2.25 \mathrm{D}$ at the 9-month visit.

\section{Case 1-right eye}

The patient was similarly diagnosed with iris capture in the right eye 17 months after vitrectomy, phacoemulsification, and IOL intrascleral fixation. Rectangular loop suture surgery was performed on this eye 20 months later. Figure 4 shows the postoperative ultrasound biomicroscopy image of the right eye. The corrected visual acuity improved from $0.5(-3.00 /-1.50 \times 180)$ to $0.6(-$ $3.00 /-1.25 \times 170)$ at the one-month visit.

\section{Case 2}

A 72-year-old female who complained of distending pain in the right eye with accompanying nausea for half a month was diagnosed with iris capture of the IOL. The patient had undergone vitrectomy, IOL removal, and IOL intrascleral fixation one year earlier for IOL complete luxation. The preoperative corrected visual acuity was 0.16 $(-4.50 /-1.00 \times 175)$ and the preoperative intraocular pressure (IOP) was $14.6 \mathrm{mmHg}$. We performed a rectangular loop suture on this patient. The suture was applied in the directions of 1:00 to 8:30 o'clock and 2:30 to 7:00 o'clock. The visual acuity was maintained at 0.16 ($4.50 /-2.00 \times 175) 3$ months later. No recurrence was observed post surgery.

\section{Discussion}

Iris capture is a common complication of IOL implantation for eyes with a capsule defect. It may be related to pupil dilation, IOL deviation or tilt, a floppy iris, or reverse pupillary block [8-10]. Mydriasis and subsequent miosis can release the iris capture, but recurrence is not uncommon, as seen in the right eye of case 1 . Choi et al. [12] reported laser iridotomy as one treatment for iris capture, however, with only a $60 \%$ success rate. Moreover, surgical techniques are available for failed cases, which include the previously described strategies of IOL repositioning and IOL exchange. In Choi et al.'s study, IOL repositioning was used in 10 eyes, but was successful in only 4 eyes. In one of the failed eyes, the IOL was subluxated and subsequently treated by refixation, but iris capture was still present. A similar case was presented in the present report (left eye of case 1). The IOL was moved from $2 \mathrm{~mm}$ behind the limbus to $3.5 \mathrm{~mm}$ by an intrascleral fixation technique. However, iris capture reoccurred after this surgery. This failure may have been related to the relaxed iris and increased pupil size under dark conditions. IOL exchange is not commonly used 

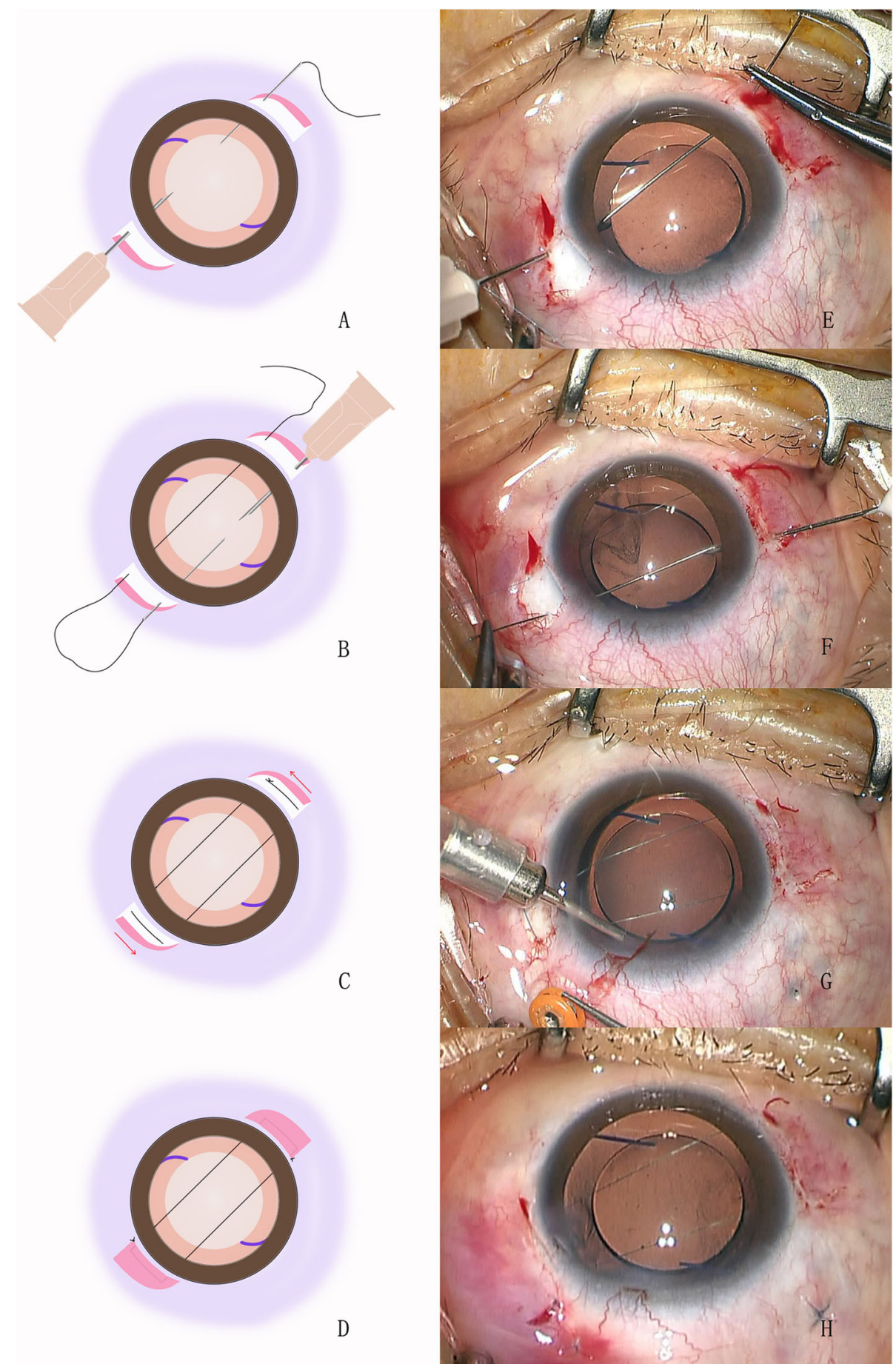

Fig. 2 Surgical procedures. a: The needle is inserted into the posterior chamber between the iris plane and IOL optic, and is withdrawn with the assistance of a 26-gauge needle. $\mathbf{b}$ : The needle is inserted at 7 o'clock and withdrawn at 2 o'clock in the same manner. c: The suture is knotted and the knot is buried by rotating the loop. $\mathbf{d}$ : The conjunctival incisions are sutured. $\mathbf{e}-\mathbf{h}$ : The figures captured from the intraoperative video recording are shown. Additional vitrectomy was performed for this patient to remove the residual vitreous and intraoperative hemorrhage

because of the resulting large injuries. Yoo et al. reported a new IOL transscleral suture fixation technique, which they named the $\mathrm{H}$ technique [15]. The suture forms a barrier between the lens and the iris to avoid postoperative iris capture, the incidence of which was $2.5 \%$. However, a complication of their technique must be considered, whereby the direction of the $\mathrm{H}$ suture was fixed and unchangeable after IOL fixation, such that 


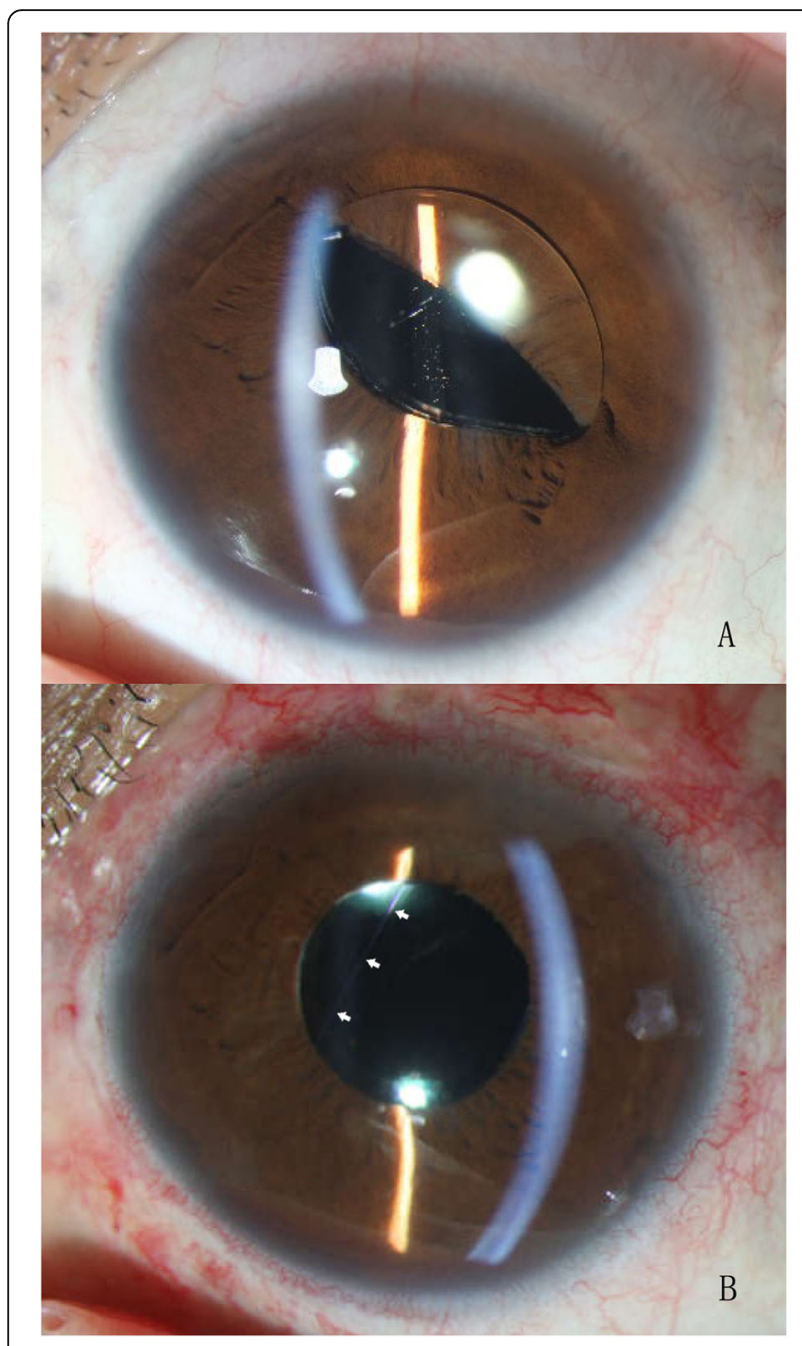

Fig. 3 The left eye in case 1: pre- (a) and postoperative (b) anterior segment photography. The white arrows indicate part of the suture

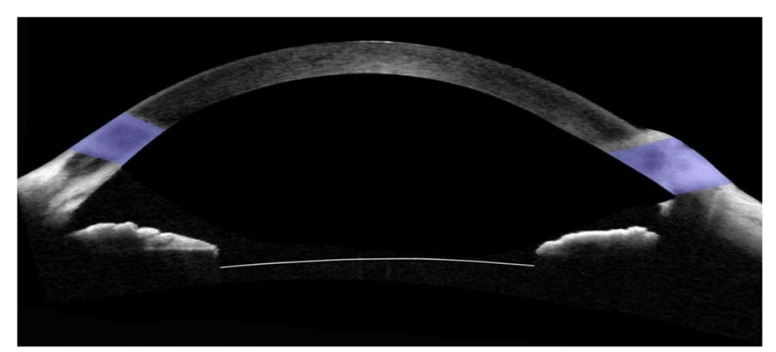

Fig. 4 Postoperative anterior segment optical coherence tomography image. The curved white line indicates the anterior interface of the intraocular lens iris capture may occur at the point where no suture passes.

The new rectangular loop suture technique prevents iris recapture by forming a barrier between the IOL optic and the iris, which is similar to $\mathrm{H}$ technique. However, with a well-designed suture direction, our technique is more individualized and precise. The applied direction was calculated according to the appearance of the iris capture before the surgery, as shown in Fig. 1. In case 1, we found that the iris capture tended to occur repeatedly in the same region of the iris, thus the suture was designed to pass behind this part of iris to prevent recurrence. However, more cases should be observed to verify this hypothesis. This technique can also correct the IOL rotation around the coronal axis by the contact between sutures and IOL optic. However, it is incapable to correct the other types of IOL dislocation.

Rho et al. [16] evaluated the influence of across-pupil sutures on the IOL optical quality and found no difference with or without sutures. In the present cases, the distance between two sutures was $3-4 \mathrm{~mm}$, avoiding the central region of the pupil, thus no abnormal vision problems occurred post surgery.

During the operation, adequate attention should be focused on the IOP. When the pressure is insufficient during suturing, a large astigmatism will occur post surgery because of intraocular pressure recovery and the tightness of the suture. Astigmatism will decrease within several months, as shown in case 1.

\section{Conclusion}

Our minimally invasive technique of rectangular loop suture can efficiently solve the complication of iris capture and is easy to perform.

\section{Abbreviations}

IOL: Intraocular lens; IOP: Intraocular pressure

\section{Acknowledgements}

We thank Robert Blakytny, DPhil, from Liwen Bianji, Edanz Editing China (www.liwenbianji.cn/ac), for editing the English text of a draft of this manuscript.

\section{Authors' contributions}

RW: Designed the study and performed surgeries; KL: Writing the article; ZL: Critical revision of the article; KL,TC, ZH,YT: Follow up the patients and collect the data; All authors have read and approved the manuscript in its current state.

Funding

Not Applicable.

\section{Availability of data and materials}

The datasets analysed during this study are available from the corresponding author on reasonable request.

\section{Ethics approval and consent to participate}

This study was approved by the Ethics Committee of the Eye Hospital of Wenzhou Medical University. All the participants signed a written consent form. 


\section{Consent for publication}

All the patients included in this study gave written consent for their personal or clinical details along with any identifying images to be published in this study.

\section{Competing interests}

The authors declare that they have no competing interests.

Received: 19 July 2020 Accepted: 17 September 2020

Published online: 25 September 2020

\section{References}

1. Grehn F, Sundmacher R. Fixation of posterior chamber lenses by transscleral sutures: technique and preliminary results. Arch Ophthalmol. 1989;107(7): 954-5.

2. Gabor SGB, Pavlidis MM. Sutureless intrascleral posterior chamber intraocular lens fixation. J Cataract Refract Surg. 2007;33(11):1851-4.

3. Hu ZX, Lin HS, Ye L, Lin Z, Chen T, Lin K, Wu RH. Sutureless Intrascleral haptic-hook Lens implantation using 25-gauge trocars. J Ophthalmol. 2018; 2018:9250425.

4. Teichmann KD, Teichmann IA. The torque and tilt gamble. J Cataract Refract Surg. 1997;23(3):413-8

5. Cho BJ, Yu HG. Surgical outcomes according to vitreous management after scleral fixation of posterior chamber intraocular lenses. Retina (Philadelphia, Pa). 2014;34(10):1977-84.

6. Shen JF, Deng S, Hammersmith KM, Kuo AN, Li JY, Weikert MP, Shtein RM Intraocular Lens implantation in the absence of Zonular support: an outcomes and safety update: a report by the American Academy of ophthalmology. Ophthalmology. 2020;127(9):1234-58.

7. Kim SK, Lanciano RC Jr, Sulewski ME. Pupillary block glaucoma associated with a secondary piggyback intraocular lens. J Cataract Refract Surg. 2007; 33(10):1813-4.

8. Lavin $\mathrm{M}$, Jagger J. Pathogenesis of pupillary capture after posterior chamber intraocular lens implantation. Br J Ophthalmol. 1986;70(12):886-9.

9. Bartholomew RS. Incidence, causes, and neodymium: YAG laser treatment of pupillary capture. J Cataract Refract Surg. 1997;23(9):1404-8.

10. Higashide T, Shimizu F, Nishimura A, Sugiyama K. Anterior segment optical coherence tomography findings of reverse pupillary block after scleralfixated sutured posterior chamber intraocular lens implantation. J Cataract Refract Surg. 2009:35(9):1540-7.

11. Bucci FA Jr, Lindstrom RL. Total pupillary capture with a foldable silicone intraocular lens. Ophthalmic Surg Lasers Imaging Retina. 1991;22(7):414-5.

12. Choi SR, Jeon JH, Kang JW, Heo JW. Risk factors for and management of pupillary intraocular lens capture after intraocular lens transscleral fixation. J Cataract Refract Surg. 2017:43(12):1557-62.

13. Galvis V, Tello A, Montezuma S. Delayed pupillary capture and noninvasive repositioning of a posterior chamber intraocular lens after pupil dilation. J Cataract Refract Surg. 2002;28(10):1876-9.

14. Khokhar S, Sethi HS, Sony P, Sudan R, Soni A. Pseudophakic pupillary block caused by pupillary capture after phacoemulsification and in-the-bag AcrySof lens implantation. J Cataract Refract Surg. 2002;28(7):1291-2.

15. Yoo YJ, Kim ET, Heo JW. Safety barricade suture for preventing pupillary capture of intraocular Lens with scleral fixation: H-technique. Retina. 2016; 36(1):206-10.

16. Rho CR, Kim MJ, Joo CK. Influence of across-pupil sutures on the optical quality of intraocular lenses. Int Ophthalmol. 2018;38(3):909-15.

\section{Publisher's Note}

Springer Nature remains neutral with regard to jurisdictional claims in published maps and institutional affiliations.

Ready to submit your research? Choose BMC and benefit from:

- fast, convenient online submission

- thorough peer review by experienced researchers in your field

- rapid publication on acceptance

- support for research data, including large and complex data types

- gold Open Access which fosters wider collaboration and increased citations

- maximum visibility for your research: over $100 \mathrm{M}$ website views per year

At $\mathrm{BMC}$, research is always in progress.

Learn more biomedcentral.com/submissions 